MicroRNA

M 7,000 (19-23 nucleotides)

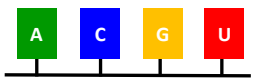

MALDI-MS

$\checkmark$ Direct, multiplex and untargeted analysis Post-transcriptional modifications
Ionic Matrix
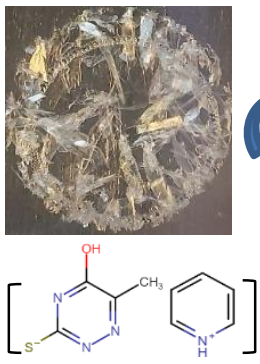

ATT-PYR

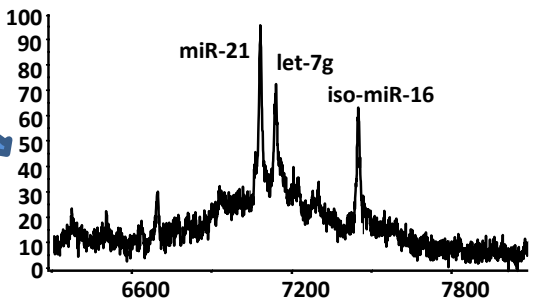

$\checkmark$ Sensitivity (fmol level) Spot-to-spot repeatability Wide applicability 


\section{Highlights}

Direct, multiplex and untargeted analysis of miRNAs is investigated by MALDI-MS.

Ionic matrices are proposed as an alternative to conventional matrices.

ATT-PYR provides higher sensitivity and improved spot-to-spot repeatability.

The analysis of miRNAs in serum samples is also explored. 


\title{
Ionic matrices for matrix-assisted laser desorption/ionization mass spectrometry analysis of microRNA biomarkers
}

\author{
Hiba Salim, Estela Giménez*, Victoria Sanz-Nebot, Fernando Benavente
}

Department of Chemical Engineering and Analytical Chemistry, Institute for Research on Nutrition and Food Safety (INSA.UB), University of Barcelona, 08028 Barcelona, Spain

"Corresponding author: estelagimenez@ub.edu

Tel: (+34) 934039778, Fax: (+34) 934021233

Keywords: Biomarker; Ionic matrix; MALDI-MS; mass spectrometry; miRNA; direct detection 


\begin{abstract}
The use of ionic matrices (IMs) was evaluated as an alternative to conventional matrices to analyze microRNAs (miRNAs) by matrix-assisted laser desorption/ionization mass spectrometry (MALDI-MS). 2, 4， 6-Trihydroxyacetophenone (THAP), 6-aza-2thiothymine (ATT) and 3-hydroxypicolinic acid (3-HPA) and their IMs with pyridine (PYR) and butylamine (BA) were studied to analyze a standard mixture of miRNAs: miR21, let-7g and iso-miR-16. Among all the studied matrices, ATT-PYR at $75 \mathrm{mg} / \mathrm{mL}$ in acetonitrile $(\mathrm{MeCN}): \mathrm{H}_{2} \mathrm{O}(50: 50, \mathrm{v} / \mathrm{v})$ was selected as the optimal. Furthermore, addition of ammonium citrate dibasic (AC) as signal enhancer was mandatory to obtain an appropriate miRNA detection. ATT-PYR provided the best sensitivity, with limit of detection (LOD) up to $5 \mathrm{nM}$ (equivalent to $1 \mathrm{fmol}$ in the spot) and excellent spot-to-spot repeatability due to the improved homogeneity of the spots compared to the conventional matrices. The applicability of the established method to direct, multiplex and untargeted analysis of miRNAs in serum samples was also investigated.
\end{abstract}




\section{Introduction}

MicroRNAs (miRNAs) are small non-coding RNAs of 19-23 nucleotides in length involved in gene regulation. They control gene expression by targeting specific messenger RNAs (mRNAs), promoting their degradation or preventing their translation [1]. MiRNAs have an important role in several cellular processes, like cell growth, tissue differentiation, apoptosis and those related to cancer like invasion, metastasis and drug resistance [1-3]. Deregulation of miRNAs has been related to the occurrence and progression of different diseases, especially cancer [2, 3]. Circulating miRNAs have been found in various biological fluids (e.g. blood, saliva and urine), protected from degradation inside extracellular vesicles or associated with RNA-binding proteins, and they are generating a great interest as biomarkers of physiological and pathological processes [4-6].

Various methods have been described for miRNA analysis, including next generation sequencing (NGS) and reverse transcription-quantitative polymerase chain reaction (RTqPCR). Although the high sensitivity, specificity and quantitative properties of these methods, they are time consuming and require high-qualified expertise, specific bioinformatics software as well as designing specific ligation adaptors, gene libraries or primers [7-9]. These issues have prompted research for alternative methods for miRNA analysis, including those based on mass spectrometry (MS) detection [10-15]. MS or hyphenated MS techniques (i.e. liquid chromatography and capillary electrophoresis coupled to MS, LC-MS and CE-MS, respectively) allow the direct, multiplex detection and quantitation of miRNAs, as well as the characterization of their post-transcriptional modifications [10-14]. However, the analysis of miRNAs by MS is rather challenging 
because miRNAs are relatively large oligonucleotides (relative molecular mass, $\mathrm{M}_{\mathrm{r}} \approx 7,000$ $7,500)$ with similar size and structure, which are prone to low ionization efficiency, complex mass spectrum, extra formation of alkali metal adducts, etc. [10-12, 16]. In addition, they are found at low concentration in biological samples, hence different strategies are necessary to enhance sensitivity, such as on-line preconcentration in CE-MS for direct untargeted detection $[10,11]$ or the use of complementary DNA (cDNA) for indirect targeted detection or targeted preconcentration in matrix-assisted laser desorption/ionization mass spectrometry (MALDI-MS) [14, 15].

MALDI-MS has been traditionally used to analyze oligonucleotides [17-23], including miRNAs [13-15]. Compared to electrospray ionization-mass spectrometry (ESI-MS) based methods, MALDI-MS has the advantages of simplicity, speed, low reagent and sample consumption and easy mass spectrum interpretation. In the typical experiments, the solutions of sample and matrix compound, which assists analyte ionization, are mixed and crystallized before applying the laser energy under the high vacuum conditions inside the mass spectrometer [24]. The conventional matrices are solid organic compounds able to absorb the applied laser energy to promote the analyte ionization process. 2, 4, 6Trihydroxyacetophenone (THAP), 6-aza-2-thiothymine (ATT) and 3-hydroxypicolinic acid (3-HPA) have been proposed to analyze oligonucleotides with disparate levels of efficiency [13-15, 17-22]. This issue is often worsened by careless or inappropriate sample-matrix preparation procedures that affect sample-matrix crystallization, hence the quality and reproducibility of the spectra. As an alternative to conventional matrices in MALDI-MS, Armstrong et al. introduced ionic liquid matrices [25], which were later 
referred to with the broader term of ionic matrices (IMs) [23]. Typical IMs are solid or liquid organic salts formed by mixing equimolar amounts of conventional matrices, such as sinapinic acid (SA), 2,5-dihydroxybenzoic acid (DHB), $\alpha$-cyano-4-hydroxycinnamic acid (CHCA), THAP, ATT and 3-HPA with an organic base like pyridine (PYR), 1methylimidazole, tributylamine or butylamine (BA). IMs usually have a melting temperature at or below $100{ }^{\circ} \mathrm{C}$, low vapor pressure and a wide range of solubilization ability for analytes. Sample-matrix preparation with IMs is easier than with conventional matrices, preventing formation of non-homogeneous spots (i.e. hot-spots) and lower mass spectrum reproducibility [23, 25-30]. Several authors have also described improved sensitivity $[29,30]$. In the last few years, IMs have been widely and successfully applied to analyze different biomolecules [23, 25-30], including oligonucleotides [23, 28-30]. However, research about miRNAs analysis has not been explored yet.

In this study, IMs were investigated for the analysis of miRNAs as an alternative to the conventional matrices typically applied to oligonucleotides. Three matrices commonly used to analyze oligonucleotides (i.e. THAP, ATT and 3-HPA) were tested and compared in positive and negative ion modes with their PYR and BA IMs. A novel preparation method for the IMs was proposed, and the best IM for miRNA MALDI-MS analysis was selected. The established method was validated in terms of spot-to-spot repeatability, linearity and limit of detection (LOD), showing improved quality parameters compared to the studied conventional matrices. The potential of the method for the analysis of miRNA biomarkers was also explored analyzing miRNAs in serum samples. 


\section{Experimental section}

\subsection{Chemicals and reagents}

All solvents and reagents were analytical reagent grade or better. Trifluoroacetic acid (TFA) was purchased from Merck (Darmstadt, Germany). LC-MS quality acetonitrile (MeCN), and methanol (MeOH) were supplied by Panreac AppliChem (Barcelona, Spain). LC-MS quality water was purchased from Thermo Fisher Scientific (Barcelona, Spain). THAP $(\geq 99.5 \%)$, ATT $(\geq 99.0 \%)$, 3-HPA $(\geq 98.0 \%)$, ammonium citrate dibasic (AC) ( $\geq 99.0 \%)$, pyridine (PYR) $(\geq 99.8 \%)$ and butylamine (BA) $(\geq 99.0 \%)$ were supplied by Sigma-Aldrich (Madrid, Spain). Synthetic miRNA: hsa-miR-21-5p (miR-21), hsa-let-7g5p (let-7g) and hsa-miR-16-5p with 3'-uridylation (iso-miR-16) were purchased from Integrated DNA Technologies (Leuven, Belgium).

\section{2 miRNA standards and serum samples}

The lyophilized miRNA standards (miR-21, let-7g, and iso-miR-16, see Table 1 for the sequence, average molecular mass (M) and modifications) were resuspended in water to prepare $200 \mu \mathrm{M}$ individual stock solutions, which were stored at $-20^{\circ} \mathrm{C}$ until use. Mixtures of the three miRNAs were prepared diluting the stock solutions with water.

Blood was collected from a healthy volunteer following standard operating procedures with the appropriate approval of the Ethical and Scientific Committees of the UB. Serum collection tubes were used as described in our previous work [31]. Serum aliquots were stored in a freezer at $-20{ }^{\circ} \mathrm{C}$ when not in use. Serum samples were pretreated using a centrifugation-assisted solid-phase extraction kit (miRCURYTM RNA Isolation Kit, 
Exiqon, Hilden, Germany), which is recommended for purification and preconcentration of small RNAs [32]. Centrifugations and incubations (with moderate shaking) were done at $25^{\circ} \mathrm{C}$. Two hundred $\mu \mathrm{L}$ of serum was centrifuged at $3,000 \mathrm{~g}$ for $5 \mathrm{~min}$ and the supernatant was collected. Then, $60 \mu \mathrm{L}$ of lysis solution was added. After vortexing and incubating for $3 \mathrm{~min}, 20 \mu \mathrm{L}$ of protein precipitation solution was added. The mixture was vortexed, incubated for $1 \mathrm{~min}$ and centrifuged at $11,000 \mathrm{~g}$ for $3 \mathrm{~min}$, before collecting the supernatant. Spiked serum samples were prepared adding at this point $0.4 \mu \mathrm{L}$ of a $50 \mu \mathrm{M}$ solution mixture of miRNAs (miRNA final concentration in serum was $0.1 \mu \mathrm{M}$ ). Then, $270 \mu \mathrm{L}$ of isopropanol was added. The mixture was vortexed, transferred to a mini spin SPE column and incubated for $2 \mathrm{~min}$. After centrifugation at $11,000 \mathrm{~g}$ for $30 \mathrm{~s}$, the mixture was successively washed with $100 \mu \mathrm{L}$ of wash solution $1(11,000 \mathrm{~g}, 30 \mathrm{~s}), 700 \mu \mathrm{L}$ of wash solution $2(11,000 \mathrm{~g}, 30 \mathrm{~s})$ and $250 \mu \mathrm{L}$ of wash solution $2(11,000 \mathrm{~g}, 2 \mathrm{~min})$. The mini spin SPE column was placed in a new collection tube and the retained miRNAs were finally eluted with $50 \mu \mathrm{L}$ of water centrifuging at $11,000 \mathrm{~g}$ for $1 \mathrm{~min}$.

\subsection{Preparation of MALDI-MS matrices}

\subsubsection{Conventional matrices}

Conventional matrix solutions were prepared daily dissolving THAP, ATT or 3-HPA in $\mathrm{MeCN}: \mathrm{H}_{2} \mathrm{O}(50: 50, \mathrm{v} / \mathrm{v})$ at a concentration of $50 \mathrm{mg} / \mathrm{mL}$ (molar concentrations were between 0.2 and $0.5 \mathrm{M}$ depending on the matrix considered) [20]. An aqueous solution of $\mathrm{AC}$ was prepared at $50 \mathrm{mg} / \mathrm{mL}$ (molar concentration was $\sim 0.2 \mathrm{M}$ ) [33]. Equivalent volumes of miRNA and $\mathrm{AC}$ solutions were mixed (e.g. $1 \mu \mathrm{L}$ ) leaving a few seconds for 
equilibration. Then, the sample-matrix solution was prepared by mixing $1 \mu \mathrm{L}$ of the previous solution and $1 \mu \mathrm{L}$ of the matrix solution [33, 34]. To improve spot-to-spot repeatability, conventional matrices were prepared at room temperature using solvents taken out immediately from the fridge at $4{ }^{\circ} \mathrm{C}$.

\subsubsection{Ionic matrices}

Organic salts were prepared following the method described by S. Carda-Broch et al. [23]. THAP, ATT or 3-HPA were dissolved in $\mathrm{MeOH}$ at a concentration of $20 \mathrm{mg} / \mathrm{mL}$. An equimolar amount of base (PYR or BA) was accurately added, the mixture was vortexed and sonicated for $5 \mathrm{~min}$ and finally evaporated to dryness with air. PYR salts were solid at room temperature whereas BA salts exhibit a glycerol-like viscosity (see Table S1 for the tentative structure, state at room temperature and average $\mathrm{M}$ ).

Under the optimized conditions, IMs were prepared at $75 \mathrm{mg} / \mathrm{mL}$ of organic salt in $\mathrm{MeCN}: \mathrm{H}_{2} \mathrm{O}(50: 50, \mathrm{v} / \mathrm{v})$ (molar concentrations were between 0.2 and $0.5 \mathrm{M}$ depending on the matrix compound considered). As with conventional matrices, equivalent volumes of a $50 \mathrm{mg} / \mathrm{mL}$ solution of $\mathrm{AC}$ and miRNA solution were mixed (e.g. $1 \mu \mathrm{L}$ ) leaving a few seconds for equilibration. Then, the sample-matrix solution was prepared by mixing $1 \mu \mathrm{L}$ of the previous solution and $1 \mu \mathrm{L}$ of the IM solution [33, 34].

\subsection{MALDI-MS}


Sample-matrix spots were prepared by using the dried-droplet method [34]. Sample-matrix solution $(0.8 \mu \mathrm{L})$ was deposited at room temperature onto the MALDI plate and allowed to evaporate to dryness in air. Spots were monitored under a stereomicroscope at $100 \mathrm{X}$ magnification. Images from the spots were taken through the objective of a $32 \mathrm{MP}$ digital camera of a Samsung Galaxy A70 cell phone (Seoul, South Korea). This way, the number, appearance (i.e. size and shape), distribution and homogeneity of the crystals in the spot were easily evaluated to optimize a reproducible sample-matrix preparation procedure.

The MALDI-TOF mass spectrometer was a 4800 Plus MALDI TOF/TOF system from AB Sciex (Framingham, MA, USA) equipped with a nitrogen laser (355 nm) and a microchannel plate detector (MCP). Data acquisition and data processing were performed using the 4800 Series Explorer ${ }^{\mathrm{TM}}$ and Data Explorer ${ }^{\circledR}$ softwares (AB Sciex). Mass spectra were acquired from 4,000 to $15,000 \mathrm{~m} / \mathrm{z}$ using the mid mass positive and negative linear modes. The final mass spectra were typically obtained as summation of 900 consecutive laser shots. Measurements were performed at a laser intensity value of 7000 (89\% of the maximum) to obtain adequate sensitivity without rapidly destroying the sample. No miRNA fragmentation was observed at this laser intensity value or higher.

\subsection{Quality parameters}

All quality parameters were calculated considering the miRNA singly charged molecular ions in positive or negative ion modes $\left([\mathrm{M}+\mathrm{H}]^{+}\right.$or $\left.[\mathrm{M}-\mathrm{H}]^{-}\right)$. The $\mathrm{m} / \mathrm{z}$ (mass-to-charge) axis of the mass spectra were externally recalibrated using as a reference let-7g. Mass accuracy for miR-21 and iso-miR-16 was calculated as delta mass $\left(\Delta M=\left|M_{\text {theoretical }}-M_{\text {experimental }}\right|\right)$. 
Spot-to-spot repeatability was evaluated as the relative standard deviation in percentage (\%RSD) of peak areas analyzing a miRNA mixture at $1 \mu \mathrm{M}$ (number of spots, $\mathrm{n}=6$ ). Linearity was studied by analyzing a miRNA mixture in the concentration range between 0.05 and $1 \mu \mathrm{M}(\mathrm{n}=3$, at each concentration level). The LODs were estimated by analyzing miRNA mixtures at low concentration, between 0.05 and $0.001 \mu \mathrm{M}(\mathrm{n}=3$, at each concentration level). The LOD level was defined as the concentration giving a signal-tonoise ratio $(\mathrm{S} / \mathrm{N})$ close to and higher than 3 . 


\section{Results and discussion}

Three of the most common matrices applied to analyze oligonucleotides by MALDI-MS (i.e. THAP, ATT and 3-HPA) [17-23], including miRNAs [13-15], were selected as a reference to investigate later the applicability of IMs. A mixture of three miRNA (i.e. miR21 , let-7g and iso-miR-16) with slight structural differences (Table 1), was analyzed using these matrix compounds as conventional matrices but also as IMs with PYR or BA. Experiments were performed in positive and negative ion modes, without any additive or using TFA $[23,26,29]$ and $\mathrm{AC}[16,20,22,23,29]$ as signal enhancers to avoid alkali adduct formation.

\subsection{Conventional matrices}

First, some preliminary experiments were performed to select the laser intensity in order to obtain an adequate sensitivity. A $1 \mu \mathrm{M}$ miRNA mixture was analyzed using the three conventional matrices, and laser intensity was investigated between 6,000 and 7,500 in both ion modes. A value of 7,000 was selected for all the studied matrices as no big difference in sensitivity was observed with higher laser intensity values and for avoiding an excessive sample destruction. The best results with THAP and ATT were obtained in positive ion mode (compare Fig. 1 and Fig. S1), and no miRNAs were detected with 3HPA (data not shown). Fig. 1 shows the mass spectra with THAP and ATT in positive ion mode at a 7,000 laser energy. As can be observed comparing the right y-axis of the mass spectra, ATT provided the best sensitivity and, in addition to the protonated miRNA molecular ions, some minor abundance potassium adducts and synthetic impurities could be detected (Fig. 1b). ATT showed an important difference between both ion modes 
(compare Fig. 1b and Fig. S1-b), in contrast to THAP, which gave similar results, although in negative ion mode the noise was slightly higher (compare Fig. 1a and Fig. S1-a). Fig. 2a and $2 \mathrm{~b}$ show the images of the spots obtained with THAP and ATT matrices, respectively. THAP gave more homogenous spots with a network-like appearance. The use of AC as signal enhancer was described for the analysis of oligonucleotides to avoid the production of metal-ion adducts when using conventional matrices [16, 20, 22, 23, 29]. In our case, the addition of AC showed an important role in miRNA detection as the studied miRNAs were not detected if $\mathrm{AC}$ was not present in the sample.

Unexpectedly, miRNAs were not detected with 3-HPA at any laser intensity, in contrast to other authors that reported this matrix for the analysis of DNA and RNA oligonucleotides $[15,20,21]$. While some authors recommended THAP and ATT for the detection of oligonucleotides having up to 25 [22] or 40 bases [19], others suggested the use of 3-HPA in all cases $[15,20,21]$. Therefore, in addition to the number of bases, the base composition and the structure of the oligonucleotides would strongly affect the performance of 3-HPA. As ATT gave the best results as a conventional matrix, this method was evaluated in terms of spot-to-spot repeatability, linearity and LOD (see Table 2). Spot-to-spot repeatability was acceptable with \%RSD of peak area values ranging between $20-23 \%$ for the studied miRNAs when analysing a $1 \mu \mathrm{M}$ miRNA mixture (n=6). Mass accuracy was the typical expected by MALDI-MS with this type of mass spectrometer, scanning in this $\mathrm{m} / \mathrm{z}$ range when external $\mathrm{m} / \mathrm{z}$ recalibration is applied (delta mass, $\Delta \mathrm{M}<1.1$ ). The method was linear between $0.05 \mu \mathrm{M}$ and $1 \mu \mathrm{M}$ with coefficients of determination $\left(\mathrm{R}^{2}\right)$ higher than 0.946 , and LODs were $10 \mathrm{nM}$ (equivalent to $2 \mathrm{fmol}$ in the spot) for the three miRNAs. 


\subsection{Ionic matrices}

Once evaluated THAP, ATT and 3-HPA as conventional matrices, they were investigated as IMs with two organic bases: PYR and BA. PYR and BA IMs were previously reported for the analysis of oligonucleotides and other biomolecules such as peptides and glycoproteins by MALDI-MS, but mainly with 3-HPA [23, 28], CHCA [25, 28-30] and SA $[25,26]$ matrices.

PYR IMs were first prepared at $0.5 \mathrm{M}$ of organic salt in $\mathrm{MeCN}: \mathrm{H}_{2} \mathrm{O}(2: 1, \mathrm{v} / \mathrm{v}, 0.2 \%$ TFA) as described by S. Carda-Broch et al. [23]. THAP-PYR and ATT-PYR did not provide any miRNA signal when the mixture of the three miRNAs at $1 \mu \mathrm{M}$ was analyzed in positive and negative ion modes at any laser intensity. Only 3-HPA-PYR gave some remarkable results, but mass spectra were not reproducible enough between spots and days. In MALDIMS, the analyte-matrix co-crystallization is essential to ensure an appropriate analyte ionization efficiency, and matrix concentration, solvents and additives play a crucial role in the crystal network formation. Therefore, some modifications were introduced in the method proposed by S. Carda-Broch et al. [23]. First, TFA was replaced by AC as an alternative signal enhancer according to the previous results with conventional matrices and because again no miRNAs were detected without any additive. Furthermore, the IM concentration was changed to $50 \mathrm{mg} / \mathrm{mL}$ (molar concentrations were between 0.2 and 0.3 M of organic salt depending on the IM considered) in $\mathrm{MeCN}: \mathrm{H}_{2} \mathrm{O}(50: 50, \mathrm{v} / \mathrm{v})$ as in the method established for the conventional matrices. Using these conditions, miRNA signals substantially increased in both ion modes with THAP-PYR and ATT-PYR (a laser intensity of 7,000 was again selected as the optimal value). Fig. 3 shows the mass spectra obtained 
with the three IMs in negative ion mode, which provided better sensitivity (compare the results in negative and positive ion modes, Fig. 3 and Fig. S2, respectively). As can be observed, miRNAs were better detected with ATT-PYR as happened with ATT matrix. THAP-PYR also promoted a relevant ionization of the studied miRNAs, but the signal intensity was lower than with ATT-PYR. 3-HPA-PYR response did not improve compared to the initial preparation method, and reproducibility was still poor. If THAP-PYR and ATT-PYR results are compared with those obtained with the conventional matrices (Fig. 1), similar profiles were obtained in the mass spectra, but sensitivity only significantly increased when using the ATT-PYR (e.g. compare the right y-axis of the mass spectrum for ATT as conventional matrix and IM, Fig. $1 \mathrm{~b}$ and Fig. 3b, respectively). This could be attributed to the composition of this IM, which favoured the energy transfer between the matrix and the miRNAs and the formation of larger miRNA-matrix cocrystals (compare the images of the spots in Fig. 2b and 2d). In general, as can be observed in Fig. 2d, with the IMs, miRNA-matrix solution seemed to crystallize in a more organized way which improved the homogeneity of the spots.

A similar study was performed with THAP, ATT and 3-HPA with BA IMs. Nevertheless, BA IMs were discarded as only ATT-BA allowed detecting the miRNAs, but the signal was poorer compared to ATT-PYR in both ion modes (e.g. compare Fig. 3b and Fig. S3a). Moreover, as can be observed in the image of Fig. S3-c, lower homogeneity of the spots was obtained with ATT-BA, which provided lower reproducibility in comparison with ATT and ATT-PYR (Fig. 2b and 2d, respectively).

From these results, 3-HPA was definitively discarded as conventional matrix or IM for MALDI-MS analysis of miRNAs, and the rest of the study was continued only with THAP- 
PYR and ATT-PYR. Further experiments were performed increasing THAP-PYR and ATT-PYR concentration from 50 to 75 and $100 \mathrm{mg} / \mathrm{mL}$. A concentration of $100 \mathrm{mg} / \mathrm{mL}$ was rapidly discarded due to solubility issues in both cases. Regarding comparison between 50 and $75 \mathrm{mg} / \mathrm{mL}$, the best signal intensity for the two IMs was obtained with $75 \mathrm{mg} / \mathrm{mL}$. Furthermore, the homogeneity of the spots was also improved in both cases at this IM concentration (compare the images of the spots in Fig. 2d and 2e for ATT-PYR by way of an example). Although THAP-PYR at $75 \mathrm{mg} / \mathrm{mL}$ gave more homogenous spots and better signal compared to $50 \mathrm{mg} / \mathrm{mL}$, sensitivity continued being lower than with ATT-PYR. Finally, solvent composition was also evaluated with ATT-PYR. Fig. 2e and $2 f$ show the images of the spots obtained with $75 \mathrm{mg} / \mathrm{mL}$ ATT-PYR in $\mathrm{MeCN}: \mathrm{H}_{2} \mathrm{O}(50: 50 \mathrm{v} / \mathrm{v})$ and (70:30 v/v), respectively. An increase of MeCN promoted crystal production and spot-tospot homogeneity, but sensitivity was reduced to less than a half, which suggested that a faster evaporation of the solvents did not favor miRNA-matrix co-crystallization. Therefore, ATT-PYR at $75 \mathrm{mg} / \mathrm{mL}$ in $\mathrm{MeCN}: \mathrm{H}_{2} \mathrm{O}(50: 50 \mathrm{v} / \mathrm{v})$ was definitively selected for the analysis of miRNAs. Fig. 4a shows the mass spectrum for a standard mixture of the studied miRNAs at $1 \mu \mathrm{M}$ with the optimized conditions.

The established method was validated in terms of spot-to-spot repeatability, linearity and LOD. As can be observed in Table 2, ATT-PYR provided excellent spot-to-spot repeatability, diminishing the \%RSD of peak area values by half due to the higher spot homogeneity compared to ATT. Linearity also improved and $\mathrm{R}^{2}$ were closer to 1 , indicating potential for quantitative analysis even without using internal standards. Finally, both methods showed similar mass accuracy, but the LODs with ATT-PYR were slightly lower than with ATT (5 nM, $1 \mathrm{fmol}$ miRNA/spot, versus $10 \mathrm{nM}, 2$ fmol miRNA/spot), which 
confirmed the possibility of enhancing sensitivity through the use of IMs, as suggested by several authors $[29,30]$.

\subsection{Application to serum samples}

Once validated the IM method with standards, miRNAs were analyzed in serum samples to confirm the applicability to complex samples. Serum samples were pretreated before the analysis using a commercially available kit for off-line purification and preconcentration of small RNAs, and then spiked with a standard mixture of miR-21, let-7g and iso-miR-16 at $0.1 \mu \mathrm{M}$. Fig. 4 shows the mass spectra for a standard mixture at $0.1 \mu \mathrm{M}$ (Fig. $4 \mathrm{~b}$ ) and for the spiked serum sample at the same concentration (Fig. 4c). As can be observed, the three miRNAs could be detected in the serum sample, although the signal was slightly lower due to the matrix complexity and the recoveries of the sample pretreatment (i.e. approximately $85 \%$ as estimated in a previous work [11]). As expected, no endogenous miRNAs were detected in non-spiked serum samples by MALDI-MS (data not shown), because the concentration of these low abundant biomarkers in healthy controls is far lower than the current LODs. Up to now, only a few authors have demonstrated that MALDI-MS methods with conventional matrices can be used to detect miRNAs in biological samples $[14,15]$. S. Kim et al. presented an indirect targeted method converting miRNAs into cDNA followed by amplification and detected concentration levels were similar to the ones reached with ATT as conventional matrix ( 2 fmol/spot) [15]. More recently, M. Konno et al have demonstrated the direct targeted measurement of miRNAs in pancreatic cancer cell cultures and serum samples by MALDI-MS after applying a preconcentration step including cDNA [14]. Therefore, the established ATT-PYR IM method could be very 
useful to improve the performance of these MALDI-MS methods that are using conventional matrices, and to develop new ones to further expand our knowledge about these important potential biomarkers.

\section{Concluding remarks}

We introduced for the first time IMs for the direct, multiplex and untargeted detection of miRNAs by MALDI-MS, as an excellent alternative to the conventional matrices. A novel method was optimized with a standard mixture of three miRNAs: miR-21, let-7g and isomiR-16. Among the investigated conditions, ATT-PYR IM at $75 \mathrm{mg} / \mathrm{mL}$ in $\mathrm{MeCN}: \mathrm{H}_{2} \mathrm{O}$ (50:50 v/v) gave the best results regarding sensitivity, with LODs up to $5 \mathrm{nM}$ (lower than LODs obtained with ATT matrix). Moreover, ATT-PYR showed improved spot homogeneity compared to conventional matrices, which provided better spot-to-spot repeatability. The applicability of the established method to biological samples was also demonstrated analyzing miRNAs in spiked serum samples, as a starting point to analyze miRNAs dysregulated in different diseases. Furthermore, it could be also explored for the quality control of novel oligonucleotide biopharmaceuticals, which are called to expand in the coming years. 


\section{Acknowledgements}

This study was supported by a grant from the Spanish Ministry of Economy and Competitiveness (RTI2018-097411-B-I00) and the Cathedra UB Rector Francisco Buscarons Úbeda (Forensic Chemistry and Chemical Engineering). Hiba Salim acknowledges the UB Solidarity Foundation and the Global Platform for Syrian Students

for the scholarships at the University of Barcelona. The authors thank Roger Pero-Gascon and Irene Fernández for their helpful assistance and advice with the MALDI-MS experiments.

The authors declare no conflicts of interest. 


\section{References}

[1] V. Ambros, The functions of animal microRNAs, Nature 431 (2004) 350-355.

[2] M. Esteller, Non-coding RNAs in human disease, Nat. Rev. Genet. 12 (2011) 861874.

[3] G. Romano, D. Veneziano, M. Acunzo, C.M. Croce, Small non-coding RNA and cancer, Carcinogenesis 38 (2017) 485-491.

[4] P.S. Mitchell, R.K. Parkin, E.M. Kroh, B.R. Fritz, S.K. Wyman, E.L. PogosovaAgadjanyan, A. Peterson, J. Noteboom, K.C. O’Briant, A. Allen, D.W. Lin, N. Urban, C.W. Drescher, B.S. Knudsen, D.L. Stirewalt, R. Gentleman, R.L. Vessella, P.S. Nelson, D.B. Martin, M. Tewari, Circulating microRNAs as stable blood-based markers for cancer detection., Proc. Natl. Acad. Sci. U.S.A. 105 (2008) 10513-10518.

[5] D. Gustafson, K. Tyryshkin, N. Renwick, microRNA-guided diagnostics in clinical samples, Best Pract. Res. Clin. Endocrinol. Metab. 30 (2016) 563-575.

[6] J. Alles, T. Fehlmann, U. Fischer, C. Backes, V. Galata, M. Minet, M. Hart, M. AbuHalima, F.A. Grässer, H.P. Lenhof, A. Keller, E. Meese, An estimate of the total number of true human miRNAs, Nucleic Acids Res. 47 (2019) 3353-3364.

[7] T. Tian, J. Wang, X. Zhou, A review: microRNA detection methods, Org. Biomol. Chem. 13 (2015) 2226-2238.

[8] K.W. Witwer, M.K. Halushka, Toward the promise of microRNAs - Enhancing reproducibility and rigor in microRNA research, RNA Biol. 13 (2016) 1103-1116.

[9] R.K.Y. Wong, M. MacMahon, J. V Woodside, D.A. Simpson, A comparison of RNA extraction and sequencing protocols for detection of small RNAs in plasma, BMC Genomics 20 (2019) 446.

[10] N. Khan, G. Mironov, M. V. Berezovski, Direct detection of endogenous microRNAs and their post-transcriptional modifications in cancer serum by capillary electrophoresis-mass spectrometry, Anal. Bioanal. Chem. 208 (2016) 2891-2899.

[11] R. Pero-Gascon, V. Sanz-Nebot, M. V. Berezovski, F. Benavente, Analysis of circulating microRNAs and their post-transcriptional modifications in cancer serum by on-line solid-phase extraction capillary electrophoresis-mass spectrometry, Anal. Chem. 90 (2018) 6618-6625.

[12] J. Vásconez, R. Pero-gascon, E. Giménez, F. Benavente, Comparison of capillary electrophoresis and zwitterionic-hydrophilic interaction capillary liquid chromatography with ultraviolet and mass spectrometry detection for the analysis of microRNA biomarkers, Talanta (2020) (in press).

[13] D.M. Wambua, M. Ubukata, J. Dane, R.B. Cody, N.H.L. Chiu, Bottom-up mass spectrometric sequencing of microRNA, Anal. Methods 6 (2014) 8829-8839.

[14] M. Konno, J. Koseki, A. Asai, A. Yamagata, T. Shimamura, D. Motooka, D. 
Okuzaki, K. Kawamoto, T. Mizushima, H. Eguchi, S. Takiguchi, T. Satoh, K. Mimori, T. Ochiya, Y. Doki, K. Ofusa, M. Mori, H. Ishii, Distinct methylation levels of mature microRNAs in gastrointestinal cancers, Nat. Commun. 10 (2019) 3888.

[15] S. Kim, J. Park, J. Na, G.Y. Jung, J. Hwang, Simultaneous determination of multiple microRNA levels utilizing biotinylated dideoxynucleotides and mass spectrometry, PLoS One 11 (2016) e0153201.

[16] A.M.B. Giessing, F. Kirpekar, Mass spectrometry in the biology of RNA and its modifications, J. Proteomics 75 (2012) 3434-3449.

[17] K. Faulstich, K. Wömer, H. Brill, J.W. Engels, A sequencing method for RNA oligonucleotides based on mass spectrometry, Anal. Chem. 69 (1997) 4349-4353.

[18] Y. Kong, Y. Zhu, J.-Y. Zhang, Ionization mechanism of oligonucleotides in matrixassisted laser desorption/ionization time-of-flight mass spectrometry, Rapid Commun. Mass Spectrom. 15 (2001) 57-64.

[19] D. V. Zagorevskii, M.F. Aldersley, J.P. Ferris, MALDI analysis of oligonucleotides directly from Montmorillonite, J. Am. Soc. Mass Spectrom. 17 (2006) 1265-1270.

[20] N.A. Hagan, C.A. Smith, M.D. Antoine, J.S. Lin, A.B. Feldman, P.A. Demirev, Enhanced in-source fragmentation in MALDI-TOF-MS of oligonucleotides using 1,5diaminonapthalene, J. Am. Soc. Mass Spectrom. 23 (2012) 773-777.

[21] J.C. Joyner, K.D. Keuper, J.A. Cowan, Analysis of RNA cleavage by MALDI-TOF mass spectrometry, Nucleic Acids Res. 41 (2012) e2.

[22] M. Šebela, Analysis and sequencing of nucleic acids by matrix- assisted laser desorption / ionisation mass spectrometry, Spectrosc. Eur. 28 (2016) 11-15.

[23] S. Carda-Broch, A. Berthod, D.W. Armstrong, Ionic matrices for matrix-assisted laser desorption/ionization time-of-flight detection of DNA oligomers, Rapid Commun. Mass Spectrom. 17 (2003) 553-560.

[24] A. El-Aneed, A. Cohen, J. Banoub, Mass spectrometry, review of the basics: Electrospray, MALDI, and commonly used mass analyzers, Appl. Spectrosc. Rev. 44 (2009) 210-230.

[25] D.W. Armstrong, L. Zhang, L. He, M.L. Gross, Ionic liquids as matrixes for matrixassisted laser desorption/ionization mass spectrometry, 73 (2001) 3679-3686.

[26] E. Giménez, F. Benavente, J. Barbosa, V. Sanz-Nebot, Ionic liquid matrices for MALDI-TOF-MS analysis of intact glycoproteins, Anal. Bioanal. Chem. 398 (2010) $357-365$.

[27] J.A. Crank, D.W. Armstrong, Towards a second generation of ionic liquid matrices (ILMs) for MALDI-MS of peptides, proteins, and carbohydrates, J. Am. Soc. Mass Spectrom. 20 (2009) 1790-1800.

[28] A. Tholey, E. Heinzle, Ionic (liquid) matrices for matrix-assisted laser desorption/ionization mass spectrometry-applications and perspectives, Anal. Bioanal. 
Chem. 386 (2006) 24-37.

[29] H.N. Abdelhamid, Ionic liquid-assisted laser desorption/ionization-mass spectrometry: matrices, microextraction, and separation, Methods Protoc. 1 (2018) 23.

[30] J.J. Jones, S.M.A.B. Batoy, C.L. Wilkins, R. Liyanage, J.O. Lay, Ionic liquid matrixinduced metastable decay of peptides and oligonucleotides and stabilization of phospholipids in MALDI FTMS analyses, J. Am. Soc. Mass Spectrom. 16 (2005) 20002008.

[31] L. Pont, F. Benavente, J. Barbosa, V. Sanz-Nebot, Analysis of transthyretin in human serum by capillary zone electrophoresis electrospray ionization time-of-flight mass spectrometry. Application to familial amyloidotic polyneuropathy type I, Electrophoresis 36 (2015) 1265-1273.

[32] Exiqon, MiRCURY ${ }^{\mathrm{TM}} \mathrm{RNA}$ isolation kit - biofluids. Instruction manual v1.7. 2015; 1-62., (2015) 1-62.

[33] E. Pedroso, N. Escaja, M. Frieden, A. Grandas, Solid-phase synthesis of circular oligonucleotides, in: P. Herdewijn (Ed.), Oligonucleotide synthesis. Methods in Molecular Biology., Humana Press, Totowa, NJ, 2005, pp. 101-125.

[34] E. Giménez, F. Benavente, J. Barbosa, V. Sanz-Nebot, Towards a reliable molecular mass determination of intact glycoproteins by matrix-assisted laser desorption/ionization time-of-flight mass spectrometry, Rapid Commun. Mass Spectrom. 21 (2007) 25552563. 


\section{Figure captions}

Fig. 1. MALDI mass spectra in positive ion mode for a $1 \mu \mathrm{M}$ miRNA standard mixture with conventional matrices: a) THAP and b) ATT

Fig. 2. Images of the spots obtained for a $1 \mu \mathrm{M}$ miRNA standard mixture with conventional matrices and IMs: a) THAP, b) ATT, c) THAP-PYR, d) ATT-PYR at $50 \mathrm{mg} / \mathrm{mL}$ in $\mathrm{MeCN}: \mathrm{H}_{2} \mathrm{O}(50: 50, \mathrm{v} / \mathrm{v})$, and ATT-PYR at $75 \mathrm{mg} / \mathrm{mL}$ in e) $\mathrm{MeCN}_{2} \mathrm{H}_{2} \mathrm{O}(50: 50, \mathrm{v} / \mathrm{v})$ and f) $\mathrm{MeCN}: \mathrm{H}_{2} \mathrm{O}(70: 30, \mathrm{v} / \mathrm{v})$.

Fig. 3. MALDI mass spectra in negative ion mode for a $1 \mu \mathrm{M}$ miRNA standard mixture with IMs at $50 \mathrm{mg} / \mathrm{mL}$ in $\mathrm{MeCN}: \mathrm{H}_{2} \mathrm{O}$ (50:50, v/v): a) THAP-PYR, b) ATT-PYR and c) 3HPA-PYR.

Fig. 4. MALDI mass spectra in negative ion mode with ATT-PYR at $75 \mathrm{mg} / \mathrm{mL}$ in $\mathrm{MeCN}: \mathrm{H}_{2} \mathrm{O}$ (50:50, v/v) (optimized conditions): a) $1 \mu \mathrm{M}$ miRNA standard mixture, b) 0.1 $\mu \mathrm{M}$ miRNA standard mixture and c) spiked serum sample at $0.1 \mu \mathrm{M}$ miRNAs.

Fig. S1. MALDI mass spectra in negative ion mode for a $1 \mu \mathrm{M}$ miRNA standard mixture with conventional matrices: a) THAP and b) ATT.

Fig. S2. MALDI mass spectra in positive ion mode for a $1 \mu \mathrm{M}$ miRNA standard mixture with IMs at $50 \mathrm{mg} / \mathrm{mL}$ in $\mathrm{MeCN}: \mathrm{H}_{2} \mathrm{O}(50: 50, \mathrm{v} / \mathrm{v})$ : a) THAP-PYR, b) ATT-PYR and c) 3HPA-PYR.

Fig. S3. MALDI mass spectra for a $1 \mu \mathrm{M}$ miRNA standard mixture with ATT-BA IM at $50 \mathrm{mg} / \mathrm{mL}$ in $\mathrm{MeCN}: \mathrm{H}_{2} \mathrm{O}(50: 50$, v/v): a) negative ion mode, b) positive ion mode and c) image of the spot. 


\section{Credit Author Statement}

H. Salim: Methodology, Investigation, Visualization, Writing - original draft. E. Giménez: Conceptualization, Supervision, Visualization, Writing - original draft, Writing - review \& editing. V. Sanz-Nebot: Writing - review \& editing, Project administration, Funding acquisition F. Benavente: Conceptualization, Supervision, Writing - review \& editing, Project administration, Funding acquisition. 
Table 1. Characteristics and average molecular mass (M) of the studied miRNAs.

\begin{tabular}{ccccc}
\hline miRNA & Length, nt & Sequence & Modifications & Average M \\
\hline miR-21 & 22 & 5' UAGCUUAUCAGACUGAUGUUGA 3' & 5' phosphorylation & 7084.22 \\
let-7g & 22 & 5' UGAGGUAGUAGUUUGUACAGUU 3' & 5' phosphorylation & 7141.23 \\
$\begin{array}{c}\text { iso-miR- } \\
\text { 16 }\end{array}$ & 23 & 5' UAGCAGCACGUAAAUAUUGGCGU 3' & $\begin{array}{c}\text { 5' phosphorylation } \\
\text { and 3' uridylation }\end{array}$ & 7451.48 \\
\hline
\end{tabular}


Table 2. Linear regression equation, linearity range, limit of detection (LOD) and spot-tospot repeatability for the analysis of miR-21, let-7g and iso-miR-16 by MALDI-MS.

\begin{tabular}{|c|c|c|c|c|c|}
\hline \multirow{2}{*}{ miRNA } & \multicolumn{2}{|c|}{ Linearity (n=3, each level) } & \multirow{2}{*}{$\begin{array}{c}\text { LOD, nM } \\
(\mathbf{S} / \mathbf{N}>\mathbf{3})\end{array}$} & \multirow{2}{*}{$\begin{array}{c}\text { Mass accuracy, } \\
\Delta M \\
(1 \mu M, n=6)^{a} \\
\end{array}$} & \multirow{2}{*}{$\begin{array}{c}\text { Repeatability, } \\
\% \text { RSD } \\
\text { Peak area }(1 \mu M, n=6) \\
\end{array}$} \\
\hline & $\mathbf{A}=\mathbf{b}^{*} \mathbf{C}+\mathbf{a}$ & Range $(\boldsymbol{\mu M})$ & & & \\
\hline $\begin{array}{l}\text { ATT } \\
\text { (positive mode) }\end{array}$ & $\left(R^{2} \geq 0.946\right)$ & & & & \\
\hline miR-21 & $A=10611 C-414$ & $0.05-1$ & 10 & 0.4 & 23 \\
\hline let-7g & $A=9540.7 C-409$ & $0.05-1$ & 10 & - & 23 \\
\hline iso-miR-16 & $A=13082 C-722$ & $0.05-1$ & 10 & 1.1 & 20 \\
\hline $\begin{array}{l}\text { ATT-PYR } \\
\text { (negative mode) } \\
\end{array}$ & $\left(R^{2} \geq 0.985\right)$ & & & & \\
\hline miR-21 & $A=15412 C+135$ & $0.05-1$ & 5 & 0.6 & 11 \\
\hline let-7g & $A=13557 C+426$ & $0.05-1$ & 5 & - & 9 \\
\hline iso-miR-16 & $A=15860 C-126$ & $0.05-1$ & 5 & 0.3 & 12 \\
\hline
\end{tabular}

a The $\mathrm{m} / \mathrm{z}$ axis of the mass spectra were externally recalibrated using as a reference let-7g. Therefore, mass accuracy for this miRNA could not be calculated. 


\section{a) THAP}
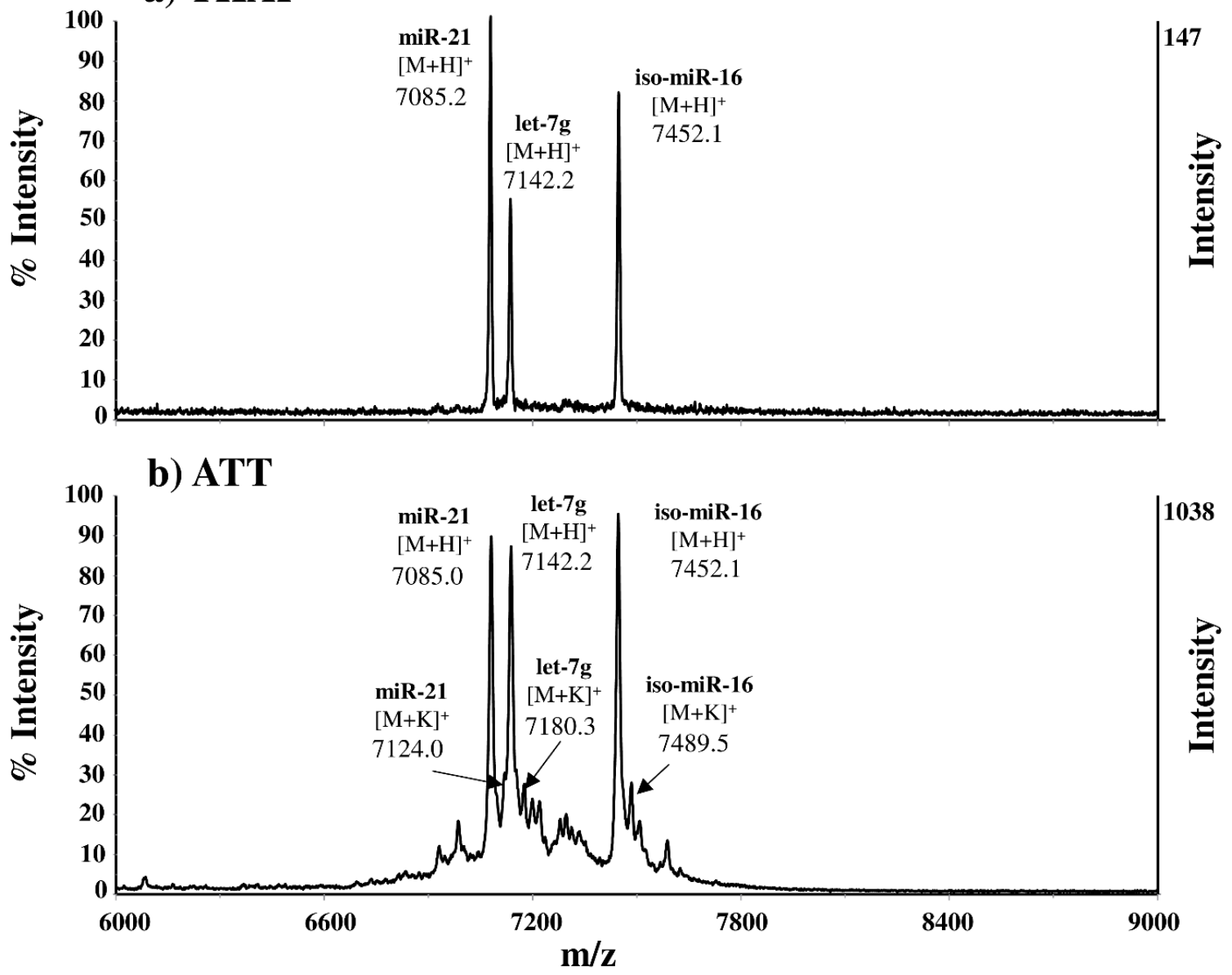

Figure 1 
a) THAP $(50 \mathrm{mg} / \mathrm{mL}$, $\left.\mathrm{MeCN}: \mathrm{H}_{2} \mathrm{O}, 50: 50, \mathrm{v} / \mathrm{v}\right)$

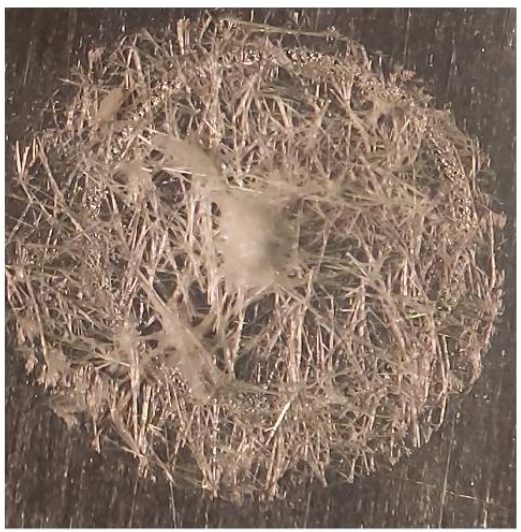

c) THAP-PYR $(50 \mathrm{mg} / \mathrm{mL}$, $\left.\mathrm{MeCN}: \mathrm{H}_{2} \mathrm{O}, 50: 50, \mathrm{v} / \mathrm{v}\right)$

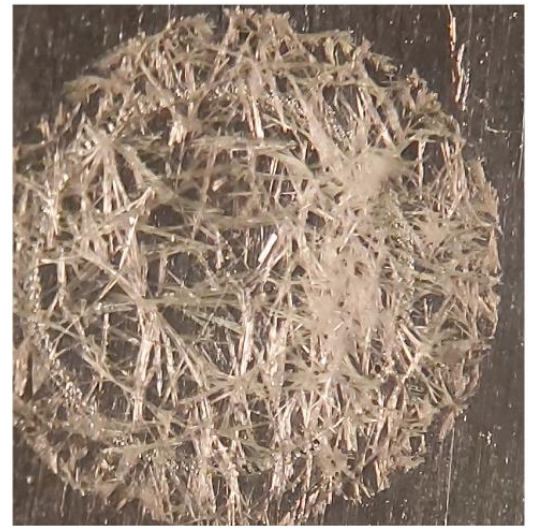

e) ATT-PYR $(75 \mathrm{mg} / \mathrm{mL}$, $\left.\mathrm{MeCN}: \mathrm{H}_{2} \mathrm{O}, 50: 50, \mathrm{v} / \mathrm{v}\right)$

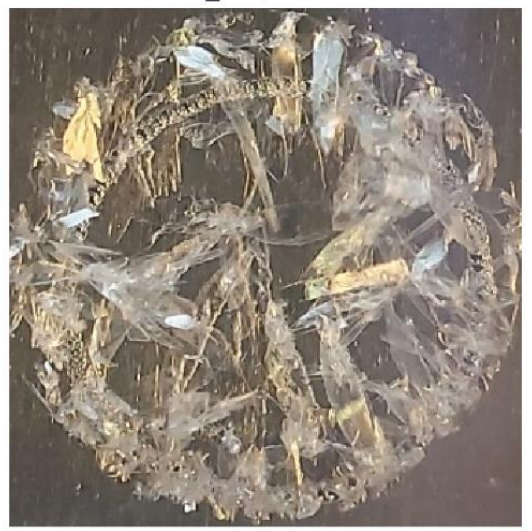

b) ATT $(50 \mathrm{mg} / \mathrm{mL}$, $\left.\mathrm{MeCN}: \mathrm{H}_{2} \mathrm{O}, 50: 50, \mathrm{v} / \mathrm{v}\right)$

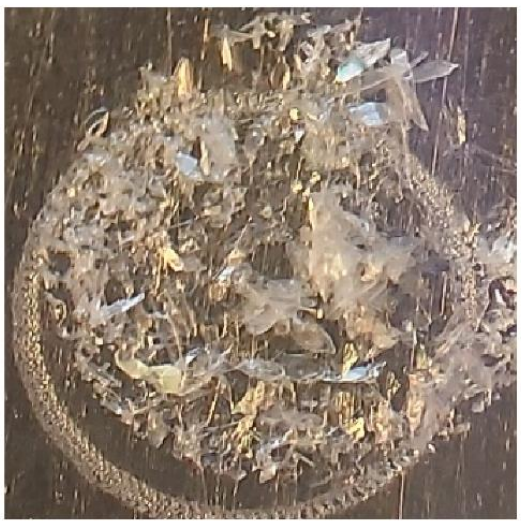

d) ATT-PYR $(50 \mathrm{mg} / \mathrm{mL}$, $\left.\mathrm{MeCN}: \mathrm{H}_{2} \mathrm{O}, 50: 50, \mathrm{v} / \mathrm{v}\right)$

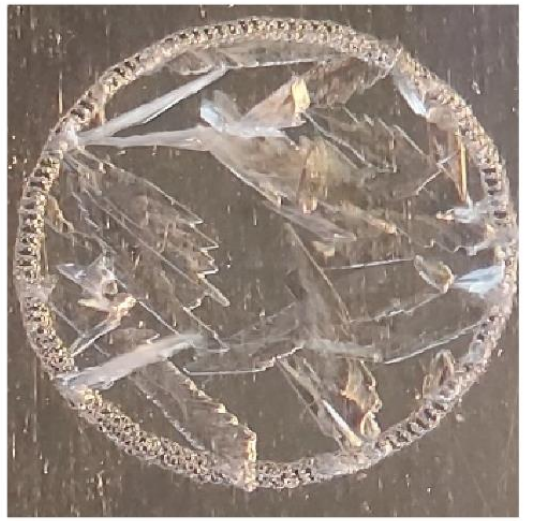

f) ATT-PYR $(75 \mathrm{mg} / \mathrm{mL}$, $\left.\mathrm{MeCN}: \mathrm{H}_{2} \mathrm{O}, 70: 30, \mathrm{v} / \mathrm{v}\right)$

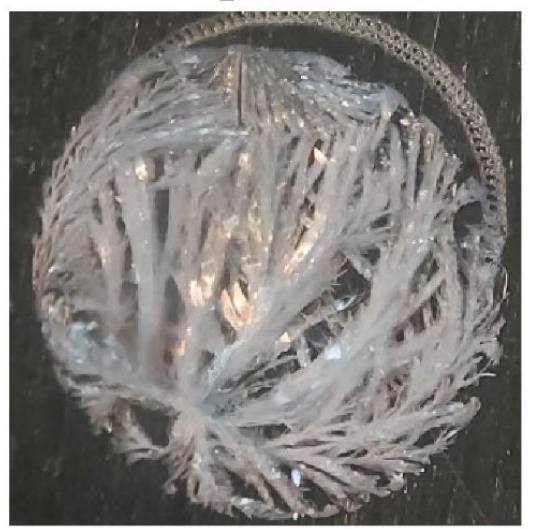

Figure 2 

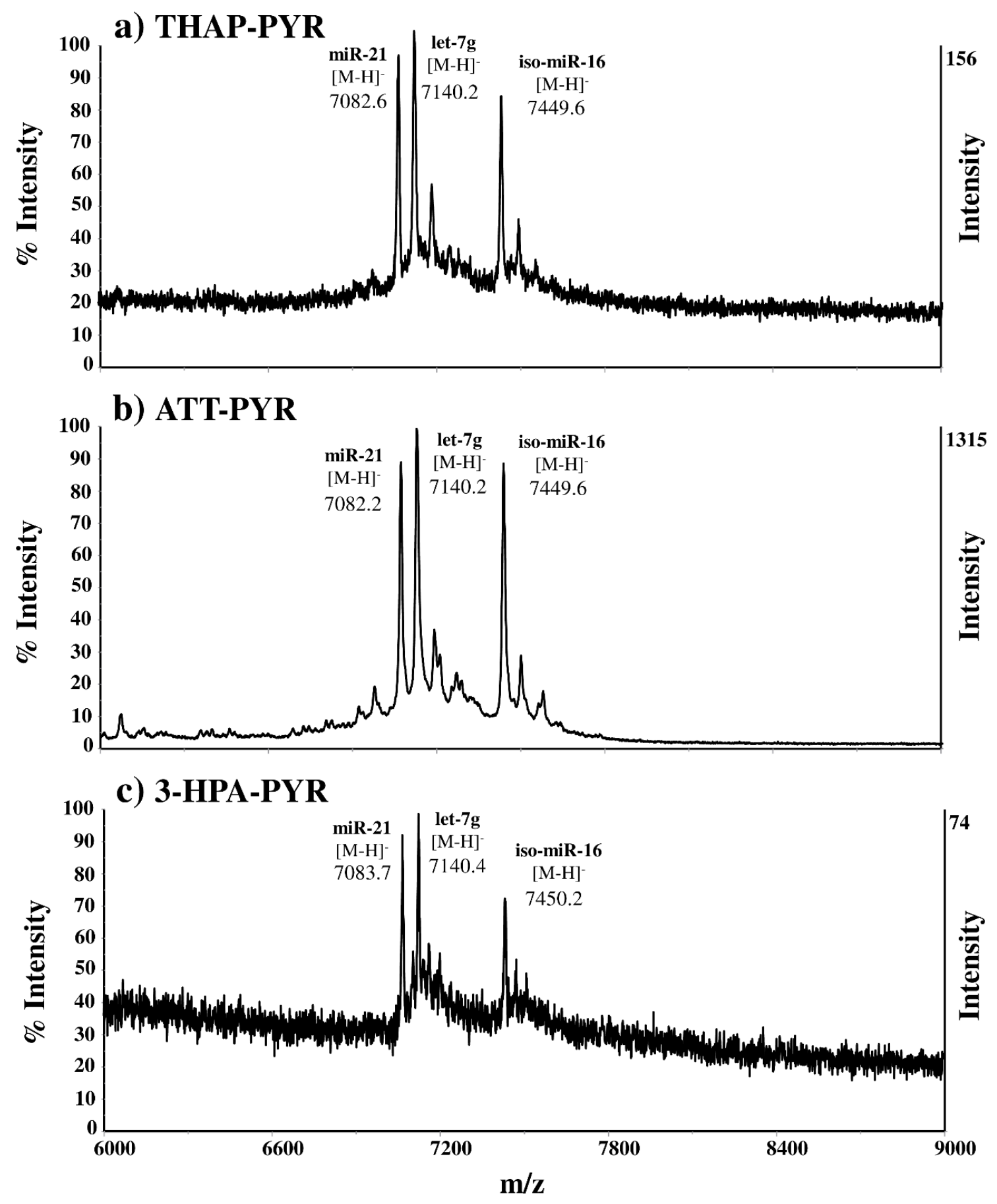

Figure 3 

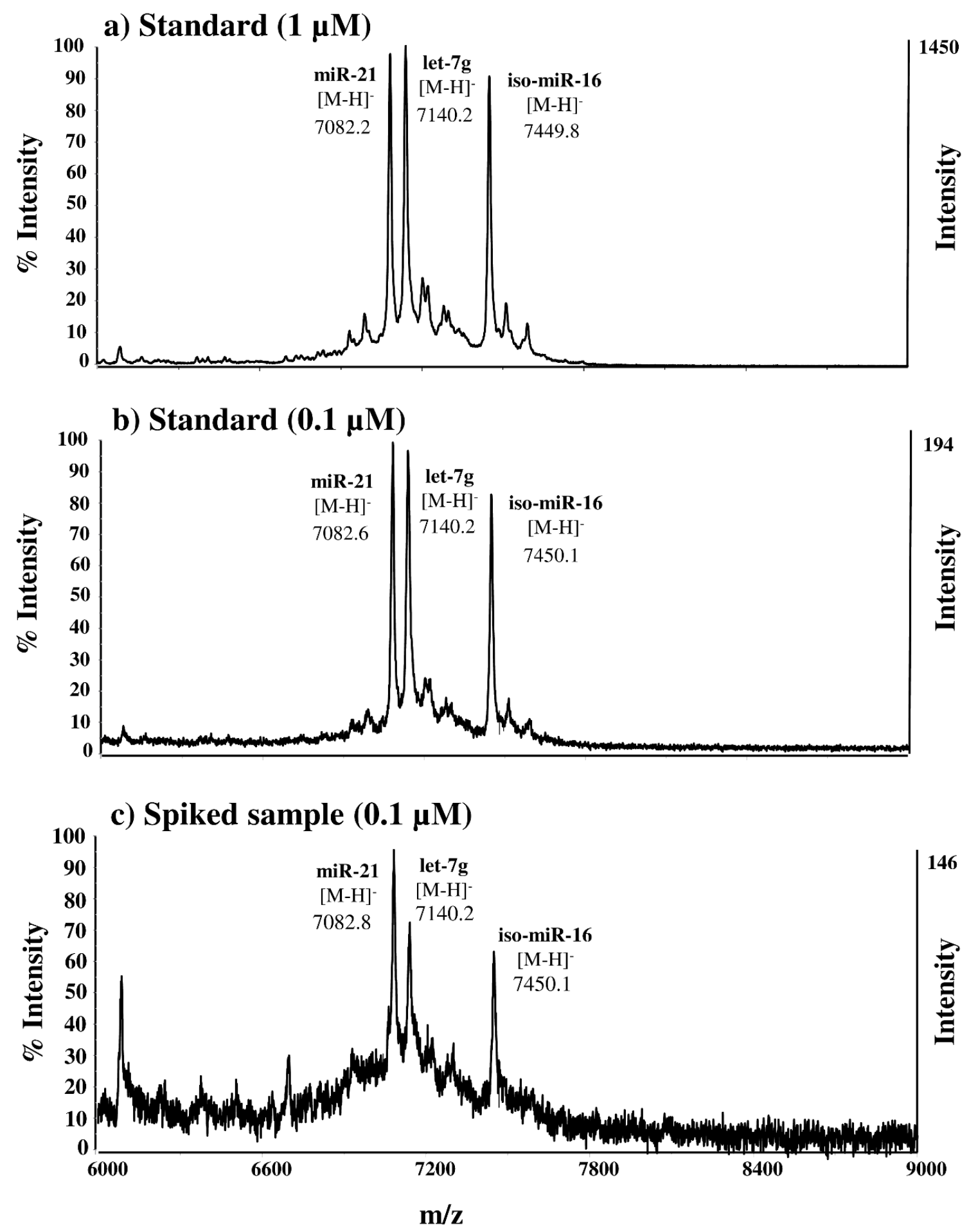

Figure 4 


\section{Supplementary Material}

\section{Ionic matrices for matrix-assisted laser desorption/ionization mass spectrometry analysis of microRNA biomarkers}

Hiba Salim, Estela Giménez*, Victoria Sanz-Nebot, Fernando Benavente

Department of Chemical Engineering and Analytical Chemistry, Institute for Research on Nutrition and Food Safety (INSA·UB), University of Barcelona, 08028 Barcelona, Spain

${ }^{\#}$ Corresponding author: estelagimenez@ub.edu

ORCID ID: 0000-0002-0700-3701

Tel: (+34) 934039778, Fax: (+34) 934021233 
Table S1. Organic salts used as ionic matrices for the analysis of miRNAs by MALDIMS. The structures of the organic salts shown are only tentative.

\begin{tabular}{|c|c|c|c|}
\hline Organic salt & Structure of the organic salt & State at $25^{\circ} \mathrm{C}$ & $\begin{array}{c}\text { Average } \\
\text { M }\end{array}$ \\
\hline THAP-PYR & & Solid & 247.25 \\
\hline ATT-PYR & & Solid & 222.27 \\
\hline 3-HPA-PYR & & Solid & 218.21 \\
\hline THAP-BA & & $\begin{array}{c}\text { Glycerol like } \\
\text { viscosity }\end{array}$ & 241.28 \\
\hline ATT-BA & & $\begin{array}{c}\text { Glycerol like } \\
\text { viscosity }\end{array}$ & 216.10 \\
\hline 3-HPA-BA & & $\begin{array}{l}\text { Glycerol like } \\
\text { viscosity }\end{array}$ & 212.12 \\
\hline
\end{tabular}


Fig. S1. MALDI mass spectra in negative ion mode for a $1 \mu \mathrm{M}$ miRNA standard mixture with conventional matrices: a) THAP and b) ATT.
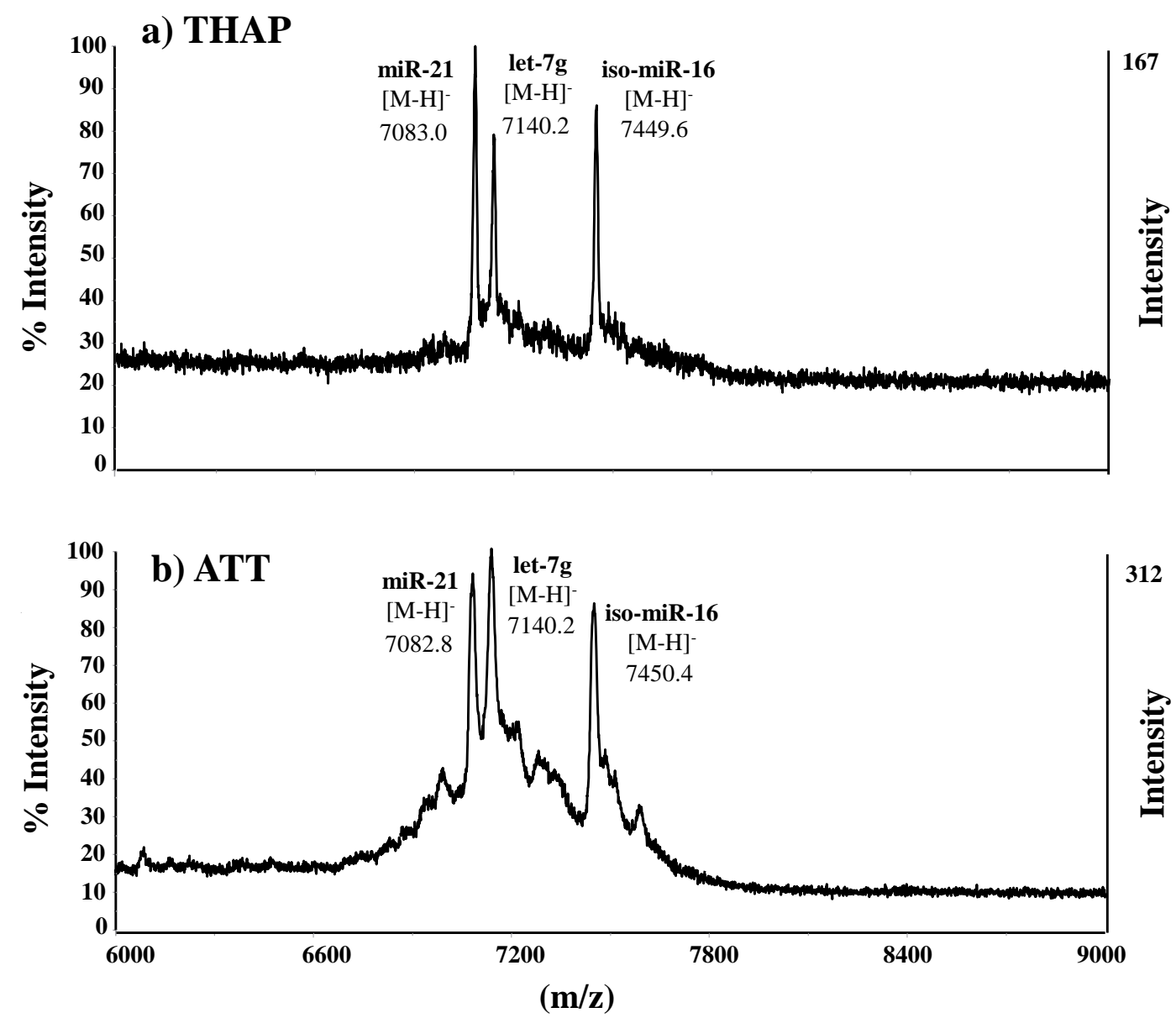
Fig. S2. MALDI mass spectra in positive ion mode for a $1 \mu \mathrm{M}$ miRNA standard mixture with ionic matrices (IMs) at $50 \mathrm{mg} / \mathrm{mL}$ in $\mathrm{MeCN}: \mathrm{H}_{2} \mathrm{O}(50: 50, \mathrm{v} / \mathrm{v})$ : a) THAP-PYR, b) ATT-PYR and c) 3-HPA-PYR.

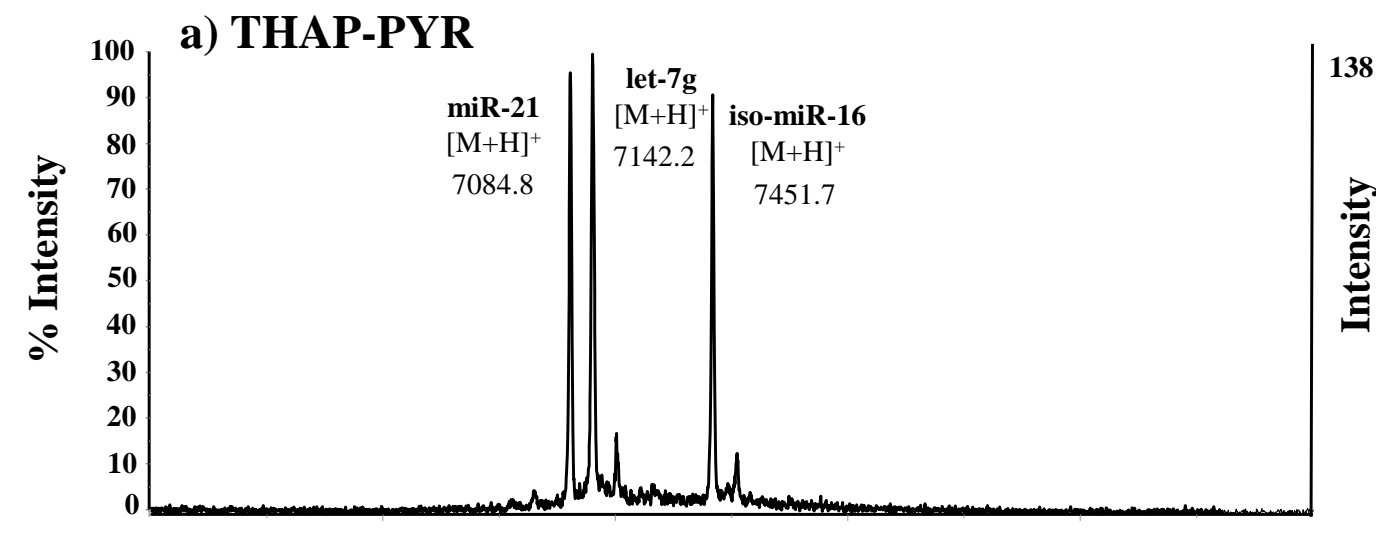

b) ATT-PYR
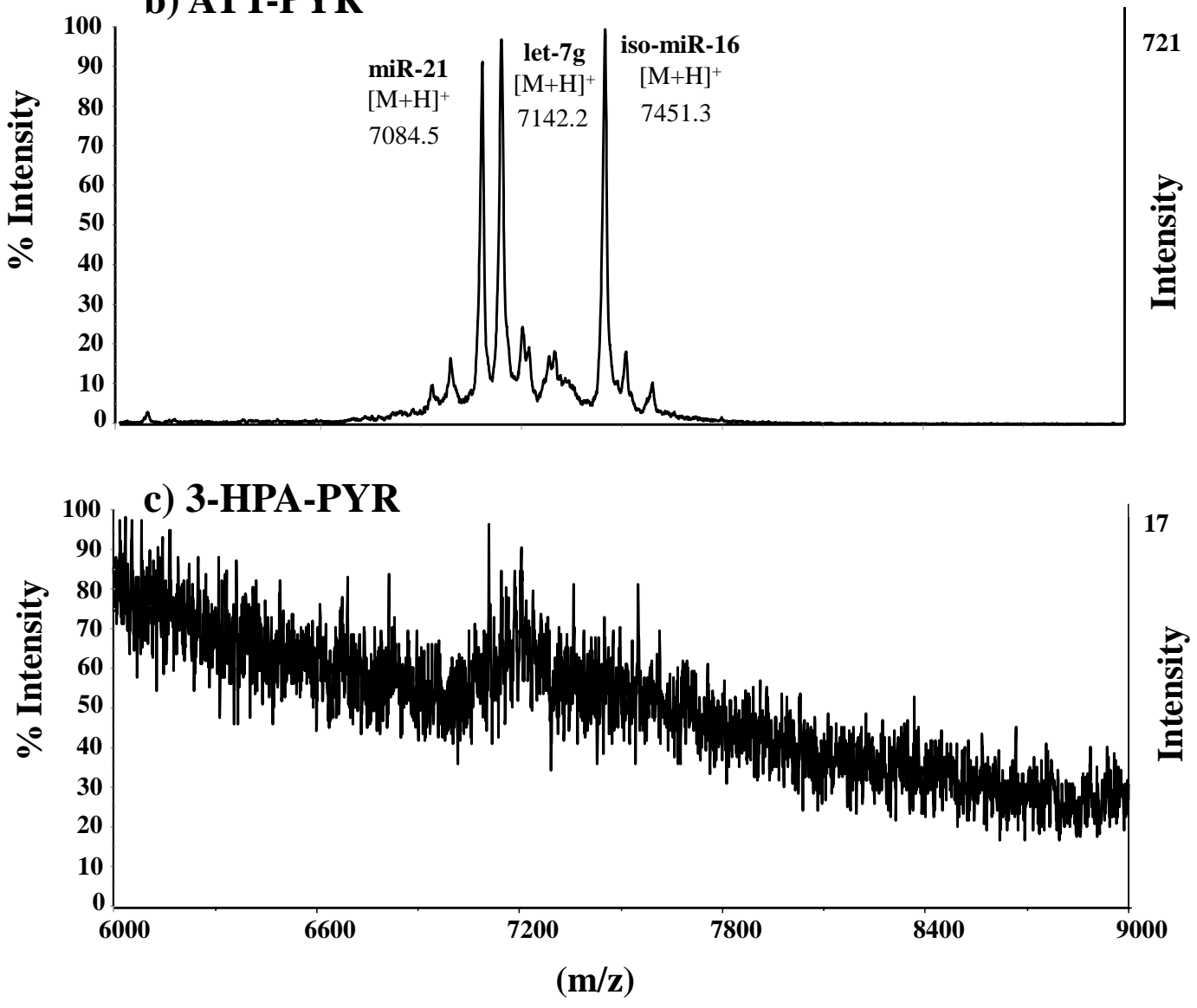
Fig. S3. MALDI mass spectra for a $1 \mu \mathrm{M}$ miRNA standard mixture with ATT-BA at 50 $\mathrm{mg} / \mathrm{mL}$ in $\mathrm{MeCN}: \mathrm{H}_{2} \mathrm{O}(50: 50, \mathrm{v} / \mathrm{v})$ : a) negative ion mode, b) positive ion mode and c) image of the spot.

a) ATT-BA (negative mode)

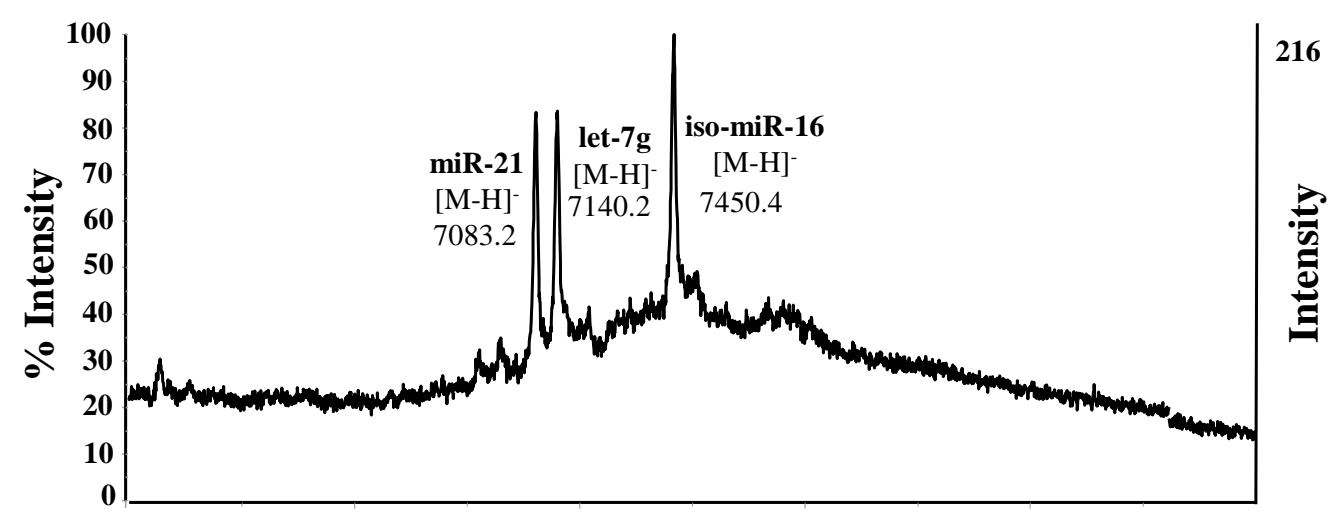

b) ATT-BA (positive mode)

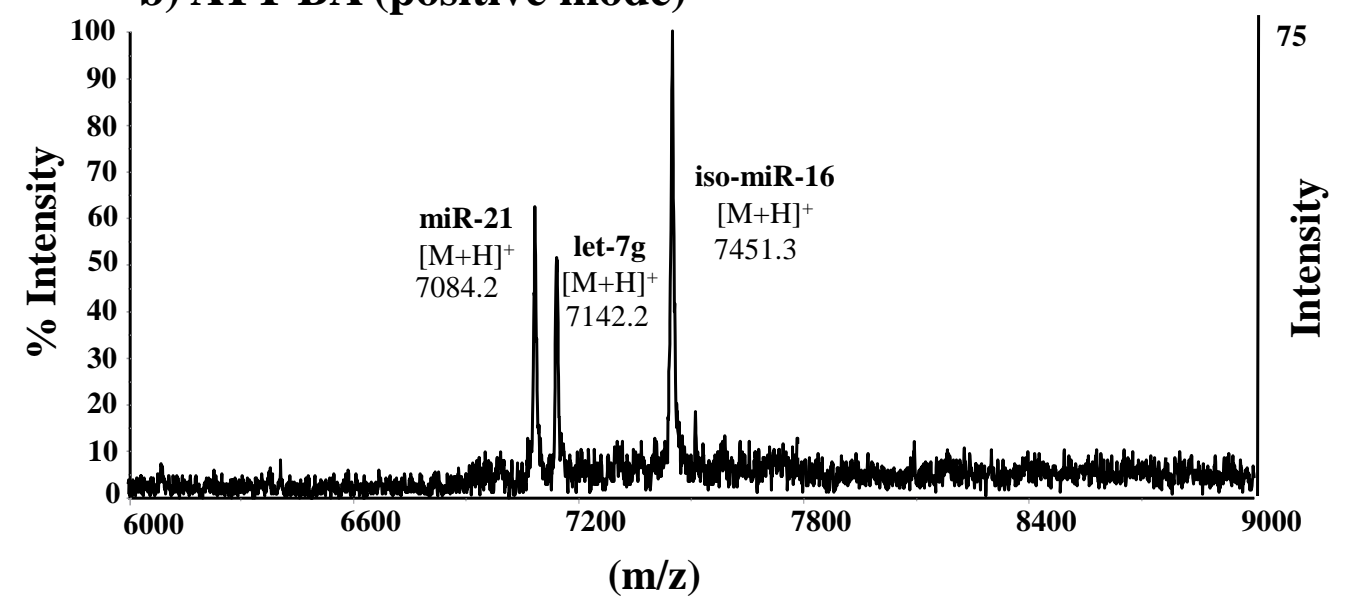

c) ATT-BA (50 mg/mL, $\left.\mathrm{MeCN}: \mathrm{H}_{2} \mathrm{O}, 50: 50, \mathrm{v} / \mathrm{v}\right)$

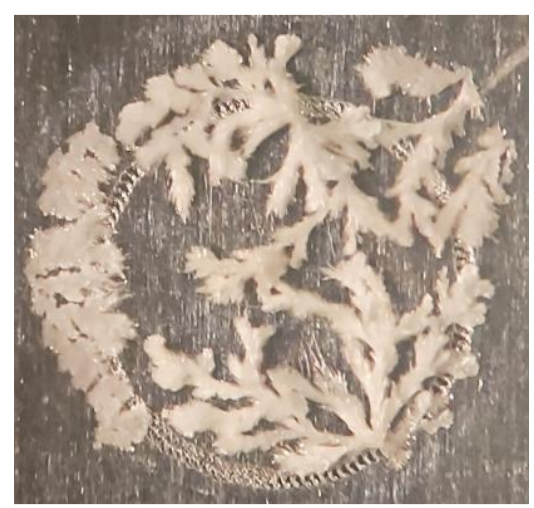

